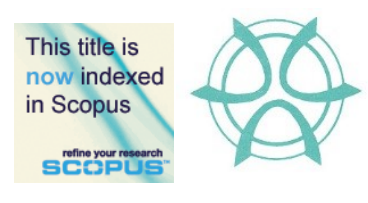

PLANNING MALAYSIA:

Journal of the Malaysian Institute of Planners

VOLUME 18 ISSUE 3 (2020), Page 179 - 189

\title{
PUBLIC TRANSPORT PLANNING: \\ LOCAL BUS SERVICE INTEGRATION AND IMPROVEMENTS IN PENANG, MALAYSIA
}

\author{
Azfizan Aziz ${ }^{1}$ and Jamilah Mohamad ${ }^{2}$ \\ ${ }^{1}$ School of Housing, Building and Planning \\ UNIVERSITY OF SCIENCE MALAYSIA \\ ${ }^{2}$ Faculty of Arts and Social Sciences \\ UNIVERSITY OF MALAYA
}

\begin{abstract}
An integrated public transport system should provide seamless travel to passengers so that they can enjoy good service connection, reasonable waiting time at interchanges, comprehensive information and an integrated ticket amongst different transport modes. Such a system is essential because it allows integrated travel by using all public transport modes that suit passengers' routes. The concept of integration in public transport, which includes physical, network, fare, information and institutional integration, generally adopts the vision of 'good practice' in terms of integration of public transport services. This research concentrates on bus service because it is the primary public transport mode in Penang, Malaysia. This work analyses the Rapid Penang Bus Operation and Network in detail by using a system of indicators derived from surveys and detailed information supplied by the operator. Several recommendations are also provided to improve the reliability, convenience, accessibility, coordinated physical effort and fair fare of bus services.
\end{abstract}

Keywords: Transport planning, public transport and integration, Penang

\footnotetext{
${ }^{1}$ ASTS at University of Science Malaysia and a Ph.D. candidate at University of Malaya. Email: azfizan@gmail.my
} 
Azfizan Aziz and Jamilah Mohamad

Public Transport Planning: Local Bus Service Integration and Improvements in Penang, Malaysia

\section{INTRODUCTION}

In recent years, integrated public transport has received considerable attention in Europe, Singapore, Hong Kong and many cities. Extensive effort has been exerted to improve the connectivity across transport modes so that public transport can become a viable alternative to car travel, thus reducing road congestion, pollutant emission and other negative effects. The concept of integration in public transport generally adopts the vision of 'good practice' in terms of integration of public transport services. Integration is about travelling from one place to another via rider-friendly intermodal facilities and interconnections. Improved integration between public transport modes helps people move around easily and reduces the costs and inconvenience of travel (Ibrahim, 2001).

People in Hong Kong can afford current transport fares with short waiting and travelling times. Coordination between transport modes minimises wasteful competition and duplication of services. Many people will use public transport services if these services offer fair fares, speed, convenience and good vehicle quality. Entering the new millennium, people need to have a good vision of the future. Continuous improvement and upgrading of the quality of the public transport system in an environmentally friendly manner can maintain the popularity of such a system and ensure a satisfactory quality of life for the future generation (Yiu, Kwok-Kin \& Antonio, 2005).

\section{PHYSICAL INTEGRATION}

Physical integration in the field of transport means that passengers can make door-to-door and multi-modal journeys in an uninterrupted manner. Close integration at an operational level amongst different transport modes should be organised (Luk, James \& Olszewski, 2005). Each transport mode performs complementary rather than competitively. Punctuality, frequency, coordination of timetables, synchronisation of arrival and departure times, operation management, adherence to safety standards and resource allocation must be consistent, uniform and standardised to achieve such an aim. High frequencies must be supported by high reliability. Timetables of public transport must also reflect close integration so that the waiting times indicated on the timetables are acceptable and achievable during peak and off-peak periods. Most bus service interchanges are located at key locations, such as jetty stations and major shopping malls (Komtar and Bukit Jambul). Good public transport interchange facilities can encourage people to use bus services in Penang Island. Through bus service interchange, passengers can easily transfer between buses and shift amongst different modes of public transport, especially in Weld Quay and Komtar. The design of public transport interchanges should enhance the service integration between buses and other public transport modes. The key issues in reliability at initial bus departure studied in this work belong to the following 
PLANNING MALAYSIA

Journal of the Malaysia Institute of Planners (2020)

categories: headway variance of bus departures from terminals, analysis of timetables and assessment of infrastructure and facilities. The headway variance of bus departures from terminals was generally found to be within the target set, suggesting that Rapid Penang is managing the scheduling of buses well.

A consolidated bus station can accommodate any future development to provide enhanced public transport systems under the Recommended Transport Master Plan Strategy for Penang State. Weld Quay would become a strategic network hub under the Master Plan, and the new bus station design would consider any future upgrade in bus rapid transit, tram or light rail. The current pedestrian walkway and associated commercial stalls between existing terminals will be under different land owners, but the provision of first-floor airconditioned commercial space in the new bus terminal would encourage the development of a consolidated new plan.

An assessment of infrastructure and facilities concentrated in the busiest bus stops in Penang will also be conducted; these bus stops include the eastbound bus stop at Hub Bukit Jambul, Komtar and the latter's associated bus stop in Jalan Penang. An immediate solution to the problem of the current onboard payment system would be to have conductors collecting payments and issuing tickets aboard buses, but this scenario would double the on-board staffing overnight with no guaranteed increase in income. Rapid Penang has reported that it is currently in the process of implementing a new smart card electronic ticketing system, which will solve the aforementioned problem. Even with smart cards, a backup fare box is still used on buses in Singapore; the same would probably be applied in the case in Penang. This adoption would benefit the many tourists and visitors to this World Heritage Site who do not know where to buy a smart card, but it could also encourage the local population to continue paying cash. Many existing bus passengers are of modest means and will be unfamiliar with and perhaps even unwilling to invest money in a stored-value card. The eastbound bus stop at Hub Bukit Jambul does not have major problems that require improvement.

\section{NETWORK INTEGRATION}

Network integration should be implemented at planning and operational stages (e.g. guaranteed interchanges) together with the coordination of infrastructures and main interchanges at the investment stage. Network integration is often interpreted as the creation of a structure where each public transport mode fulfils a specific role in the system by utilising its relative advantages (Luk, James \& Olszewski, 2005). A related keyword is 'coordination' because network integration also relates to the links between long-distance and local public transport networks (including specialised public transport services). The headway variance of bus arrivals at terminals is influenced by delays en route, such as traffic congestion, and the results for bus arrivals at terminals are much worse 
Azfizan Aziz and Jamilah Mohamad

Public Transport Planning: Local Bus Service Integration and Improvements in Penang, Malaysia

than those for arrivals, suggesting that this is a problem in Penang Island. Bus journey speeds have also been investigated for buses crossing GeorgeTown between Weld Quay and Komtar and found to be much lower for routes using the south-eastern section of Lebuh Chulia, where three sets of traffic signals have been observed to delay buses significantly throughout the day.

The assessment of infrastructure and facilities shows that many of the streets plied by buses in Penang are unsuitable for the development of physical bus priority measures, such as bus lanes or high-occupancy vehicle lanes, because they are too narrow. These measures ideally require divided three-lane carriageways to accommodate two lanes per direction for mixed traffic and allow for the passage of emergency vehicles during accidents and breakdowns. Similar to narrow streets, bus lanes may also be subject to congestion caused by illegal parking or loading encroachment; if this congestion is not properly regulated, it might cause a problem on narrow streets. Additionally, motorists' compliance with bus lane usage is related to the number of buses running along these lanes. A bus lane with few buses is likely to be encroached upon, and the general rule of thumb for a bus lane is to have one bus per minute or 60 per hour for the period of operation; however, this can be reduced in places such as Singapore where motorists' compliance is good. Traffic signals in Penang also have long cycle times and no coordination between junctions close to each other, and this can cause delays and bunching of buses.

\section{TICKETING AND FARE INTEGRATION}

An integrated ticket system is based on the principle of joint ticketing through fares to allow passengers to complete their journeys without any additional charge for transferring from one mode to another in an integrated public transport system. Fare integration enables passengers to use a single fare card to avail of multiple transit services involving transfers between modes. The integrated fare should be reasonable. Fare discounts and concessions should be made (i.e. the total fare must be lower than the sum of individual fares when more than one mode is involved) to enable the system to succeed. The higher the level of concessions and discounts is, the more passengers are attracted (Luk, James \& Olszewski, 2005). Although passengers can transfer within the network, the number of transfers within a period needs to be specified. Bus services in Penang Island has no integrated fare. Thus, passengers need to pay for transfer from one mode to another. However, passengers could adopt an alternative approach. To encourage people to use the public transport system and enhance coordination, bus service operators often give discounts to passengers. Passengers are offered different levels of transfer discounts on trips through interchange schemes between buses and other participating transport modes via the use of smart cards. To some extent, an interchanging scheme is generally welcomed by passengers because they can enjoy fare discount and convenient interchanging locations. 
PLANNING MALAYSIA

Journal of the Malaysia Institute of Planners (2020)

Previous recommendations indicated that Rapid Penang should ensure that the use of the proposed smart card electronic ticketing system would be beneficial for passengers so that cash payment at the fare box can be discontinued. In Singapore, cash fare is at least $70 \%$ higher than the stored value smart card fare for the first two stages of bus trips up to $4.2 \mathrm{~km}$; gradually, it decreases to about $20 \%$ higher for $40 \mathrm{~km}$ trips. Affordability of fares requires a detailed study, but general comparisons can be made between the fares of Rapid Penang and Rapid KL. The fares for Rapid KL are approximated from the zone-based fare system operating in the capital, but they are generally equivalent to those paid in Penang. Although the initial fare in Penang is more expensive than that in KL, fares in KL increase with decreasing distance (SPAD, 2015). Salaries are generally high in the capital, but the cost of living in Penang is lower than that in KL. Whether the roughly equivalent fares mean lower affordability in Penang is difficult to tell, but this might explain the low mode share of public transport. It might also imply that the scope for increasing the fares in the implementation of electronic ticketing in Penang is small. Penang's distance-based fare increments are in the second group of cities. Although the scope of increasing the fares in the implementation of electronic ticketing in Penang is small, the increase in cash fares with distance could be adjusted effectively to provide the previously recommended discount for the proposed smart card electronic ticketing system in terms of cash fare.

\section{INFORMATION INTEGRATION}

Bus services should provide an improved level of services and facilities to passengers. Passengers should be able to obtain information about all alternative forms of public transport easily and conveniently. Information must be displayed at stations, bus terminals and interchange areas. Passengers should also be able to obtain up-to-date information through customer hotlines, brochures, Internet platforms and passenger information display boards. Effort should be exerted to develop a comprehensive transport information system of public transport services that will provide a table of fares, route information, departure times and arrival times (Luk, James \& Olszewski, 2005). The following information on Rapid Penang's website has been made available for review during this study: information currently available at bus terminals and bus stops and a proposed new bus stop poster. Rapid Penang's website also has the following information available: stored value cards, bus route diagrams, schedules, a trip planner with a drop-down menu of options, 'places of interest' function with a drop-down menu of options, bus stop estimated time of arrival function using the bus stop code as the input and information on fares and concessions.

However, very little information is available at bus stops, if Hub Bukit Jambul was excluded from this classification. Several bus stops do not even have a Rapid Penang post and logo to inform the travelling public that stage buses 
Azfizan Aziz and Jamilah Mohamad

Public Transport Planning: Local Bus Service Integration and Improvements in Penang, Malaysia

actually stop there (hence, they could be confused with other private street furniture). The problem is that bus shelters are owned and operated by a thirdparty organisation, which owns the advertising rights. Rapid Penang needs to pay an advertising rate to post bus service information on the panels of bus shelters, but it is allowed to erect its own signs at the sides. The websites related to other public transport systems around the region are not as user-friendly as they could be, and Rapid Penang could take its cue from Google Maps.

Other potential improvements to information provision/promotion fall into the following categories: information on streets, information on major nodes and other types of information. Information on streets primarily concerns bus stops, which pose an issue in the way information/advertising is managed. Nevertheless, Rapid Penang has proposed a new bus stop poster with considerable useful information on it. The proposed poster and additional advertising content have to be specifically prepared for each bus stop, which would require extensive effort and high costs for Rapid Penang, with each poster representing a limited catchment of potential viewers. Another issue is the updating/maintenance of the information at each individual bus stop or changing it when a new traffic management scheme affects bus routes, similar to what happened in George Town during the study. A glass or Perspex bus stop sign casing with inserted paper signage is the most cost-effective means of dealing with this issue.

\section{INSTITUTIONAL INTEGRATION}

Many agencies at the central level are involved in public transport. The involvement of too many authorities with an unclear scope and function is another source of problems. Regulatory bodies, including local authorities, can produce plans, but without an agreement or clear definition of their respective jurisdiction, the plans are likely to fail. Local authorities, through regulatory bodies, lack the authorisation to plan and implement appropriate public transport policies. Other issues that contribute to this present state of deficiency are inadequate planning resources (staff) and lack of local involvement in public transport planning. Whether or not the functions of the existing authority are clearly defined, the operators still have to keep bus transport services operating (Azfizan \& Jamilah, 2013).

With the exception of Penang, none of the local authorities in Malaysia is given the responsibility to plan the transport system for their respective areas. The present organisational structure widens the gaps of planning and implementation between central and local agencies. Public transport in Penang must be coordinated and improved further depending on the development of the comprehensive strategy or the Public Transport Plan, which could include a mixture of improvement infrastructures, greatly improved marketing system for public transport, enhanced public transport services, reorganised and streamlined 
public transport at the strategic level, guidelines and improved statutory requirements for the planning of public transport, encouragement for local authorities in the planning and control of public transport, increased number of transport personnel through vigorous training and integration of public transport with urban development. The support of the public and politicians and the cooperation of the federal government are required for the urban public transportation system to be improved. The Penang government believes that collaboration and partnership between parties, including the government, private sectors and transport operators, are crucial to implementing transport planning.

\section{LOCAL BUS SERVICE IMPROVEMENTS}

This research on integration concepts provides numerous implications for those involved in the planning of and policy-making for public transport. A number of implications in terms of policies related to bus services provided for general passengers are also established.

\subsection{Convenience, Simplicity and Reliability}

Integrated public transport delivers fast, frequent, reliable services to passengers. Service frequency, coverage and operating hours can be synchronised into a standard. It also provides easy access to numerous destinations and allows people to reach the places they wish to visit. Accessibility is improved as the network develops in central or strategic growth areas. Feeder services promote easy access to main transport points and offer choices of transport mode to passengers. Integrated tickets make travel easy and simple for passengers. The provision of adequate facilities makes journeys safe, comfortable and convenient. An integrated public transport system results in enhanced quality and a fair, equitable, safe system for people. Integration reduces costs, and thus, fares. A healthy competition maintains reasonable fares and ensures that passengers will have choices. Fares will be set at an economical level. The introduction of rebates for transferring and zoning would also benefit passengers.

Many existing bus routes are circuitous and serve a series of destinations; consequently, they have extended journey times. Many locations close to city centres also exhibit extensive duplication between routes, with several bus routes travelling within the same bus corridor. Similarly, the current vehicular/passenger ferry service between Butterworth and GeorgeTown treats passengers as second-class users, limiting their usage to certain services and providing them with a sub-standard travel experience. A much more integrated, simplified, efficient, passenger-friendly public transport network than the one at present needs to be created. A series of new design principles have been developed and used to achieve this aim. These design principles are as follows: 
Azfizan Aziz and Jamilah Mohamad

Public Transport Planning: Local Bus Service Integration and Improvements in Penang, Malaysia

a) Establishment of a core network that offers frequent service and is simple, direct and easily understood;

b) Provision of a network of regular feeder services;

c) Promotion of operating efficiency;

d) Need for a hierarchy of services;

e) Provision of convenient transfers and good network accessibility; and

f) Provision of adequate and up-to-date information.

Many factors, such as current provision, planning goals, viability and value for money and network change mechanisms and processes, need to be considered when developing bus services that can be implemented (SPAD, 2015).

\subsection{Frequent Services and Easy Access by Passengers}

Bus and ferry operators should promote an integrated and frequent service. Then, the operating characteristics of operators, such as operation hours, headways, rolling stock and interchange points, route design stops and service coverage and frequency, can be closely integrated. Hence, highly integrated service, convenient interchange and a barrier-free environment can be provided to passengers. Through the removal of interchange ticket gates, passengers could enjoy seamless transfer and fast journey between two terminals or bus stations and can do away with the cost of a second boarding charge when making a transfer at the interchange points of two networks. Moreover, bus services should be restructured and integrated with ferry operation. Unnecessary overlap services should be reduced, and additional direct routes should be provided to areas without sufficient public transport services. These services include route planning, adjustment of operating hours, fare readjustment, relocation of bus stops, placement of transfer points and provision of service information. Frequent services should be maintained during peak hours. In addition, headways should be kept to a level that meets commuters' needs, especially in areas with low demand or outside the catchment of bus services. Peak and off-peak headways can be adjusted to be integrated with ferry operation and meet passengers' demands. In the provision of high-frequency bus services, 5- and 10-minute headways are acceptable for peak and off-peak periods, respectively. The transfer time from one mode to another is another issue. Five minutes of walking for a transfer between ferry and bus services are generally acceptable. Improvements in bus network and careful selection of new bus routes are also required to avoid unnecessary duplication.

Normally, the service punctuality of bus services in Penang Island is unacceptable, except when incidents or accidents occur. Frequent causes include problems in overhead lines or signals and bus breakdowns. Bus operators should look into these issues. Suitable technical and workmanship improvements should be made to maintain system reliability. Regular maintenance should be performed 
PLANNING MALAYSIA

Journal of the Malaysia Institute of Planners (2020)

to avoid unreliability. Passengers always complain about bus operators' poor customer service and quality. Reliability, frequency and punctuality are their primary concerns. Improvement of bus services is required in different areas, such as frequency of service, reliability, safety and comfort. The rationalisation of bus services and bus stops is a major initiative for integration.

\subsection{Coordinated Physical Integration}

Most of the public interchanges in Penang are located adjacent to the main transport hubs. Improved physical integration between operators can be smoothly implemented depending on whether convenient interchanges are provided. Good public transport interchanges provide convenience and close connectivity to facilitate intermodal transfers. Under integration, bus services will provide feeder services to bus terminals, and frequent services from bus terminals to major destinations should be maintained regularly to synchronise service connections. The operating hours and timetables between services should be optimised to reduce waiting times. Operators must ensure that the first and last scheduled services between modes are fully synchronised. The arrival and departure times of bus services between modes should be coordinated, and the gap between the first and second departures should not exceed five minutes at peak periods.

For enhanced service, the coverage and routes of bus services between modes should be designed to maximise the coverage and minimise the walking distance of passengers. The design of future bus terminals should shorten walking distances and closely connect stage and feeder buses. The stops of bus services must be designed and located to provide increased coverage for easy pick up and drop off of passengers. Bus stops or major bus transfer stops should be situated between modes at the stations or within a short walking distance of less than five minutes to destinations. Passengers are thus given easy access to nearby bus stations and transfers from bus services to other feeder modes through interchanges.

\subsection{Fair Fare, Quality Facilities and Integrated Information}

A fully integrated fare does not exist in Penang. A partnership amongst railway (Butterworth), ferry and bus services may provide a significant contribution to the establishment of an integrated fare. Public transport operators individually use their own fare and zoning systems. If service integration can be undertaken, fare and zone systems should be restructured. Fares, including concessions and discounts, need to be aligned. Reorganisation of zoning should be implemented to reduce duplicate fare charging. The proposed combined network must be divided into a set of zones on the basis of the distance (in kilometres) between zones. Fares should be calculated using the number of zones made for the journey and should be kept at reasonable levels. Although passengers can make free transfers within an integrated network, limitations should be set to prevent abuse. 
Azfizan Aziz and Jamilah Mohamad

Public Transport Planning: Local Bus Service Integration and Improvements in Penang, Malaysia

The number of transfers should be limited within a specified period. Transferring discounts should be allowed, and rebates should be offered to all ticket holders in an integrated public transport system. Concession fares for people aged 60 and above, full-time students and children should be continued.

To encourage people to use the public transport system, safer and more convenient pedestrian facilities than those established before must be provided for accessing interchanges or main transport hubs. The provision of quality pedestrian connections is essential in linking district centres to public transport hub stations, including weatherproof pedestrian facilities and bridges. The design of road crossings and footpaths should consider passengers' safety and connectivity in order to shorten the distance to the main transport points. Integrated information on public transport modes, such as route numbers, headways, fares and zones, timetables, locations of stops and stations and connection services, should be made available. In addition, accurate, clear and updated information on the use of the intelligent transport system and information technology can help passengers make decisions regarding their travel. The extent of integration depends on the relationship amongst three key operators, namely, railway, ferry and bus services. Good coordination can be secured by institutional integration. Initially, this aim can be achieved through the merger of the opportunities provided by bus, ferry and railway. Institutional integration should facilitate central planning of service levels, coordinated timetables between services, coordinated major routes, implementation of an integrated ticket system and maintenance of standard fares, concessions and zones.

\section{CONCLUSION}

Public transport, especially bus service, in Penang needs to be upgraded and improved. The current network must be simplified, and its service should be made increasingly reliable through integration. Partnership between modes can contribute to integration and serve as a step towards fully integrated public transport. Railway (Butterworth), ferry and bus services should be coordinated to achieve modal integration. The integration of public transport takes time and funds to achieve. It faces many obstacles and difficulties, and a collaborative cooperation platform should be provided by the government and operators. Although an integrated public transport system will support our society and economy, its impacts need to be considered. Therefore, the local government and APAD need to develop a balanced public transport strategy to address the challenges in Penang Island. Good planning and coordination and collaboration between the government and operators are important criteria to achieve this aim. APAD with the public is necessary to minimise social exclusion and enhance social cohesion. 
PLANNING MALAYSIA

Journal of the Malaysia Institute of Planners (2020)

\section{REFERENCES}

Angela, H. (2005). Integrated transport planning in the UK: from concept to reality, University of the West of England. Journal of Transport Geography, 65, 10241036.

Akihiko, S., \& Yukimasa, M. (2015). Development of bus location system with smartphone and effect of providing regional information added on bus information. Journal of the Eastern Asia Society for Transportation Studies, Vol. $10,1311-1322$

Azfizan, A. \& Jamilah, M. (2013). Urban public transport in Penang: some policy considerations. Paper presented at the 10th International Conference of Eastern Asia Society for Transportation Studies, Taiwan.

James, L. (2013). Road \& transport research: integrated public transport in Singapore and Hong Kong. Transport Reviews, 21(3), 124-139.

Konopatzki, M. (2005). From vision to reality: SMRT's approach to integration and multi-modal transportation, Proc. workshop on integrated transport. UTTP Asia Pacific Division. November 15-16, 2001, Singapore. (also published in Journal of Institution of Engineers Singapore, 42(3), 37-41.

Luk, J., \& Olszewski, P. (2005). ITS measures and integrated transport in Singapore, Proc. 23rd Conf. Of Australian Institutes of Transport Research CAITR 2001, Melbourne, Australia

Muhammad, F. I. (2003). Improvements and Integration of a Public Transport System: The Case of Singapora, $205-216$

Herbert, K., \& Marta, A.K. (2016). Integrated operational transportation planning in theory and practice. European Journal of Operations Research, 165, 657-667.

Penang State Structure Plan. (2020). Department of Town and Country Planning (Penang Branch), Malaysia.

Pejabat Setiausaha Kerajaan (SUK) Negeri Pulau Pinang. (2015). Penang transport master plan strategy: the public transport improvement plan. Penang State. Government Printing Office

Suruhanjaya Pengangkutan Awam Darat. (2015). Land Public Transport BILL 2010, Malaysia.

World Bank Group. (2006). PPIAF: Urban bus toolkit - toolkit and options for reforming bus system. Hanoi, Vietnam.

Received: January 2020. Accepted: $10^{\text {th }}$ May 2020 